\title{
A escrita feminina e as narrativas da Copa de 2010 através das crônicas "Tiro Livre"
}

\author{
The feminine writing and the 2010's World Cup narratives \\ through the chronicles "Tiro Livre"
}

\author{
Leonardo Turchi Pacheco \\ Universidade Federal de Alfenas (UNIFAL), Alfenas/Brasil \\ Doutor em História Social da Cultura, UFMG \\ leonardoturchi@gmail.com
}

Bárbara Gonçalves Mendes Mestre em Psicologia Social, UFMG

RESUMO: 0 texto teve como objetivo debater as divergências e convergências no que tange à possibilidade de uma escrita feminina, para além da lógica binária de gênero. Para tanto, procuramos pensar a diversidade que o termo "mulheres" implica, tendo em vista como as normas de gênero vigentes na sociedade, por meio de dinâmicas de poder, constroem o que é esperado das pessoas às quais esse gênero é atribuído, alijando-as do mundo da escrita e do mundo futebolístico. Para pensar tais temáticas e as concessões dadas às "mulheres" para a participação no mundo público, nesse caso expresso pelo jornalismo esportivo, foi feita a análise das crônicas "Tiro Livre" sobre a Copa do Mundo da África do Sul. A escolha dos textos se deu pelo fato de que eles guardam especificidades: desde 2009, são publicados em um jornal de grande circulação no estado de Minas Gerais, bem como são escritos por uma "mulher".

Palavras-Chave: Escrita feminina; Futebol; Copa do Mundo.

ABSTRACT: The aim of this paper was to debate about the convergences and divergences from the possibilities of a feminine writing detached from the binary gender logic. In order to discuss the diversity of the category "woman" we chose to explore the dynamics of power established by the social construction of gender through its norms, which dictates what gender a person can relate to, excluding "women" to participate, talk or even write about football. In this way in this paper, we will further discuss and analyze those themes exhibiting the concessions given to "women" to participate in the public sphere, conveyed in this case by the sport journalism, through the "Tiro Livre" chronicles written in virtue of the South Africa's World Cup. It is important to emphasize that we chose those chronicles for its specificities: since 2009 they were written by a "woman" on the most widespread and popular newspaper of the state of Minas Gerais, Brazil.

KEY WORDS: Feminine writing; Football; World Cup. 


\section{INTRODUÇÃO}

Após a leitura do abrangente trabalho de André Ribeiro sobre o jornalismo esportivo no Brasil; ${ }^{1}$ do capítulo dedicado, por Bernardo Buarque de Hollanda, ao resgate da ascensão, hegemonia e queda do Jornal dos Sports; ${ }^{2}$ do artigo de José Carlos Marques sobre crônica esportiva no Brasil através das representações da Copa do Mundo por alguns periódicos paulistas e cariocas; ${ }^{3}$ e da recente tese de André Couto sobre cronistas esportivos no Jornal dos Sports, que o autor denomina "donos das letras", 4 surge uma evidência incômoda e uma lacuna a ser explorada: somente o último faz menção a "mulheres" 5 cronistas esportivas no jornalismo impresso brasileiro.

Ao analisar os cronistas - temas que se propunham a abordar e estilos que possuíam - do Jornal dos Sports, Couto os separa em quatro grupos. ${ }^{6} 0$ primeiro grupo nomeia de eruditos; o segundo, de jornalistas/repórteres; o terceiro, de jornalistas polêmicos e o quarto, de mulheres cronistas. Pois bem, no quarto grupo, ele identifica duas cronistas: Inah de Morais e Florita Costa. Ambas são descritas como um "caso à parte", raro na crônica esportiva. Ambas estão localizadas, pelo autor, à sombra de seus maridos. Inah de Morais era esposa de Prudente de Moraes Neto, neto do ex-presidente da república Prudente de Moraes, enquanto Florita Costa era esposa de Flávio Costa, técnico do Flamengo e da Seleção Brasileira.

\footnotetext{
${ }^{1}$ RIBEIRO. Os donos do espetáculo.

${ }^{2}$ HOLLANDA. O cor-de-rosa: ascensão, hegemonia e queda do Jornal dos Sports entre 1930 e 1980.

${ }^{3}$ MARQUES. A função autor e a crônica esportiva no Brasil: representações da Copa do Mundo em alguns jornais paulistas e cariocas.

${ }^{4}$ COUTO. Cronistas esportivos em campo: letras, imprensa e cultura no Jornal dos Sports (1950-1958).

É necessário fazer um adendo sobre as aspas em "mulheres". Seguindo o exemplo de AZEREDO. Preconceito contra a "mulher", (e o ampliando), resolvemos colocar, em todo o texto, os termos que se referem aos gêneros como "mulher(es)", "homem", "menino" e afins, entre aspas - salvo em casos de citação direta, já que não se configuram como nossas palavras. Isso se deve a dois motivos: o primeiro é o fato de que não há uma essência que determine os sujeitos e o segundo é por, ainda lembrando da diversidade de sujeitos que se enquadram nesse binarismo, entender que nesse texto não contemplamos todas as formas de se reconhecer como "mulheres" ou "homens".

${ }^{6}$ COUTO. Cronistas esportivos em campo.
} 
Inah de Moraes cobria o turfe-hipismo e Florita Costa escrevia uma crônica que abordava questões organizacionais do time do Flamengo e outra chamada "notas femininas", que mais se assemelhava a uma coluna social, como indicou o próprio Couto. Ocupavam espaços pouco prestigiosos no periódico e, como leva a crer o autor, escreviam no Jornal dos Sports por sua aproximação com nomes do circuito político e cultural do Rio de Janeiro:

Além da herança política familiar de seu marido (e primo também), tinha uma aproximação com um círculo de amigos na área cultural bem seleto como Manuel Bandeira, Cândido Portinari e Mário Filho. Esta aproximação abria espaços em jornais como o $J S$ que davam pouquíssimas oportunidades para autoras e cronistas mulheres acerca dos esportes, tornando Inah uma das raras exceções de seu gênero. Cabe lembrar que apesar de não proporcionar espaços para cronistas no jornal, o $J S$ também reafirmava a visão do período sobre possíveis interesses que poderiam ler o jornal, como a longeva coluna "Notas Femininas". Na verdade, o objetivo deste espaço no jornal era dedicar dicas para o papel que a mulher invariavelmente deveria exercer na sociedade: a função e dona de casa, cuidadora do lar, do marido e dos filhos. Zeladora dos bons costumes e dos valores familiares. ${ }^{7}$

Percebe-se, com base nesse relato, quão limitada era a participação de "mulheres" no jornalismo esportivo, sendo que boa parte das figuras femininas lembradas são ligadas a emissoras de rádio e televisão. ${ }^{8}$ No que tange especificamente à escrita de crônicas esportivas, ${ }^{9}$ apenas dois nomes são lembrados, ainda que com diversas ressalvas. Além disso, destaca-se o fato de que apesar de uma grande aproximação da crônica esportiva com contexto futebolístico, no contexto brasileiro,10 nenhuma dessas "mulheres" cobriu efetivamente o futebol, que dirá uma Copa do Mundo.

Como se sabe e nunca é demais relembrar, os esportes, mais especificamente o futebol, são, em sua maioria, reservas de domínio masculino. Dunning, ${ }^{11}$ em um texto clássico, procurou evidenciar, por meio da abordagem

\footnotetext{
${ }^{7}$ COUTO. Cronistas esportivos em campo, p. 185.

${ }^{8}$ RIBEIRO. Os donos do espetáculo, p. 220-221, 292

${ }^{9}$ COUTO. Cronistas esportivos em campo, p. 183-191.

${ }^{10}$ COSTA; NETO; SOARES. Crônica esportiva brasileira: histórico, construção e cronista.

${ }^{11}$ DUNNING. O esporte como um domínio masculino: observações sobre fontes sociais da identidade masculina e suas transformações.
} 
teórica eliasiana, as desigualdades entre os sexos nessa esfera social. É importante mencionar que esse autor, assim como a escola teórica à qual ele se vincula, para compreender essas desigualdades, utiliza-se da categoria sexo. ${ }^{12}$ Por outro lado, encerrados em viés mais contemporâneo e menos pautados em um discurso biologicista, bem como partindo de uma perspectiva teórica feminista, Therberge ${ }^{13}$ e Hargreaves ${ }^{14}$ (esta última inclusive pensando o jornalismo esportivo) adotam a categoria gênero para refletir sobre práticas, representações e discursos que produzem diferenças e desigualdades no campo do esporte.

De acordo com as autoras supracitadas, a categoria gênero é importante para refletir sobre as relações estabelecidas no campo do jornalismo esportivo que trata do futebol, por ser uma das dimensões fundamentais para a construção de hierarquias sociais. Segundo elas, as dinâmicas sociais assimétricas estariam pautadas nas relações de poder que permeiam as construções dos gêneros na sociedade. Assim, as formas hegemônicas de gênero, que apresentam modelos de atos e condutas desejáveis, acabam por ser mecanismos de regulação "a través del cual se producen y se naturalizan las nociones de lo masculino y lo femenino".15

Trata-se, portanto, de uma construção que rege o que é considerado masculino ou feminino, com base em uma "metafísica da substância", ou seja, corpo e gênero se ligam desconsiderando outras possibilidades de subjetivação. ${ }^{16}$ Vale ressaltar, nesse ponto, que a perspectiva da qual parte esse texto é contrária a essa lógica binária. Sexo e gênero são entendidos, portanto, como mecanismos de controle que partem de um mesmo princípio biologizante. Assim, eles acabam não se diferindo, como pensado outrora, em que um (sexo) era considerado referente à biologia e o outro (gênero) à cultura. ${ }^{17}$ Vale, também, acrescentar que o tornar-se

\footnotetext{
${ }^{12}$ Consideramos relevante mencionar que partindo do aporte teórico no qual esse trabalho foi embasado, gênero e sexo não são necessariamente diferenciados, na medida em que ambos se tratam de construções discursivas evocadas para enquadramento dos corpos e sujeitos.

${ }^{13}$ THERBERGE. Gender and sport.

${ }^{14}$ HARGREAVES. Sporting females.

${ }^{15}$ BUTLER. Deshacer el género.

${ }^{16}$ BUTLER. Problemas de gênero.

${ }^{17}$ BUTLER. Problemas de gênero.
} 
sujeito passa pelo sistema sexo-gênero ${ }^{18}$ e envolve constantes negociações com tais normas vigentes na sociedade.

Em esportes como o futebol, essas negociações passam pela distensão das normas que veem a masculinidade como hegemônica e a heterossexualidade como compulsória, passando a significar, ao longo da história, essa atividade esportiva. No caso brasileiro, desde cedo, "meninos" são socializados e aprendem que há uma relação direta entre masculinidade, virilidade e futebol. Assim, eles são incentivados de forma coercitiva - de maneira a não romper e reforçar as normas da tríade sexo-gênero-orientação sexual - a torcer por uma equipe, praticar o esporte, falar sobre (comentar entre os amigos) tudo o que envolve essa atividade. Por outro lado, as "mulheres" não têm acesso à mesma socialização, sendo o mundo esportivo tido como um veto. Tudo se passa em meio a uma lógica de socialização estabelecida, na qual "meninas" não podem ter acesso a essas atividades sob o perigo de macular o que é estabelecido pela tríade sexo-gêneroorientação sexual. Aquelas que se atrevem a ultrapassar essa fronteira são acusadas de desestabilizar a ordem instituída e tida como natural. Para estas, recaem as alcunhas de "mulher-macho", "sapatão", "lésbicas”, entre outros epítetos tomados como desqualificadores que indicam que elas ocupam um espaço, uma posição que não lhes cabe nessa esfera social.

Nesse sentido, parece-nos que não é permitido às "mulheres" jogar, observar, falar e escrever sobre futebol. Ademais, parece-nos, também, que esse esporte só poderia ser observado, escrito e falado sob a perspectiva das masculinidades, concedendo à norma culturalmente construída um estatuto de natureza essencial dos gêneros.

Ora, no caso da escrita, tanto Clastres ${ }^{19}$ e Levi-Strauss ${ }^{20}$ quanto Foucault ${ }^{21} \mathrm{e}$ Bourdieu $^{22}$ demonstraram como escrever, saber e poder se relacionam para produzir discursos hegemonicamente autorizados para dizer "verdades", estabelecer espaços, posições e relações de dominação.

\footnotetext{
${ }^{18}$ RUBIN. O tráfico de mulheres: notas sobre a "economia política" do sexo.

${ }^{19}$ CLASTRES. Da tortura nas sociedades primitivas.

${ }^{20}$ LEVI-STRAUSS. Lições de escrita.

${ }^{21}$ FOUCAULT. A ordem do discurso.

${ }^{22}$ BOURDIEU. A economia das trocas linguísticas.
} 
Em Clastres, a escrita se torna lei, memória e indicativa de pertencimento através de rituais de tortura e escarificações sobre os corpos dos iniciados nas "sociedades primitivas". Já Levi-Strauss, ao narrar seu encontro com os Nambiquara em Tristes Trópicos, celebra a relação da escrita não somente como um meio de comunicação e conhecimento, mas, sobretudo, como um elemento de exercício de dominação. Como elucidava o autor: "Não se tratava de conhecer, reter ou compreender, mas de aumentar o prestígio e a autoridade de um indivíduo - ou de uma função - às custas de outrem". 23

Assim, é necessário apontar que o direito à fala e à escrita são excludentes, como também são os discursos, segundo Foucault,"24 possíveis dentro do "jogo de verdades". Isso passa porque existem, em cada sociedade, enunciações que podem ser feitas livremente e outras que são interditadas a determinados sujeitos. Portanto, não somente quem fala ou escreve, mas também sobre o que e para quem se fala ou se escreve são processos inseridos em um regime de poder que produz e é produtor de distinções sobre a própria fala, a própria escrita e os espaços legítimos e legitimados da expressão dessas. É nesse sentido que Bourdieu indica que "o uso da linguagem, ou melhor, tanto a maneira como a matéria do discurso, depende da posição social do locutor que, por sua vez, comanda o acesso que se lhe abre à língua da instituição, à palavra oficial, ortodoxa, legítima". ${ }^{25}$

Retomando o contexto ao qual nos debruçamos nesse trabalho, ocorre que, dentro da área esportiva, são poucos os que falam, bem como é seleto o grupo para quem se fala. No campo do jornalismo esportivo, mais especificamente, são poucos os privilegiados que possuem a autoridade para escrever sobre a Copa do Mundo. Geralmente, essas pessoas são as que possuem maior "capital profissional" no campo. Isso advém da posição social e dos espaços que ocupam, das relações sociais que construíram durante a carreira, das distinções que possuem em relação ao tempo e à competência profissional. Essas são as pessoas convocadas e, portanto, autorizadas a falar nessas situações. Vale ressaltar, também, que toda

\footnotetext{
${ }^{23}$ LEVI-STRAUSS. Lições de escrita, p. 281.

${ }^{24}$ FOUCAULT. Verdade e poder.

${ }^{25}$ BOURDIEU. A economia das trocas linguísticas, p. 87.
} 
essa qualificação diz muito de uma questão que permeia o mundo da escrita esportiva: o gênero.

Esse fato torna-se evidente mesmo em períodos específicos, como a Copa do Mundo, nos quais surgem espaços pontuais para que não jornalistas escrevam sobre o evento. Apesar de uma aparente abertura, não há uma ruptura nas relações hierárquicas estabelecidas nesse campo.

Talvez pela periodicidade e particularidade das Copas do Mundo - um evento quadrienal de duração mensal que evoca uma comunhão de identidades nacionais jornais e revistas, especializadas ou não em futebol, convidem profissionais proeminentes de outras áreas do conhecimento para escreverem sobre suas percepções do que envolve as partidas, dentro ou fora dos gramados. Mas a diversidade solicitada para esse momento específico do mundo do futebol se limita à profissão desempenhada por quem escreve, como podemos ver em Marques, ${ }^{26}$ ao refletir sobre a "função autor" dos cronistas que cobrem Copa do Mundo.

Em sua exposição, o autor identifica quatro grupos que são "convocados" para escrever nos periódicos do Rio e São Paulo a partir da Copa de 1990. No primeiro grupo, estariam localizados os jornalistas esportivos que escrevem sobre futebol cotidianamente; no segundo, estariam cronistas do caderno de cultura e os escritores de renome com grande apelo popular e que não necessariamente estariam vinculados ao periódico; no terceiro, os jornalistas de outros editoriais e, no quarto grupo, as crônicas seriam escritas por personalidades e celebridades do mundo do futebol, do cultural, da política e da economia.

Nesses casos, existe a possibilidade que outros discursos sejam enunciados por outros atores que não somente os discursos de "homens" profissionais do campo do jornalismo esportivo. Como afirma Marques:

0 recurso utilizado pelos jornais de chamar profissionais de outros editorias para comentar Copas do Mundo tem o intuito justamente de oferecer outras visões sobre o futebol - diferentemente das ideias comuns presentes nas análises dos jornalistas esportivos. 0 universo polifônico da crônica brasileira ao longo de mundiais de futebol reflete a diversidade que advém com a presença de um contingente de

${ }^{26}$ MARQUES. A função autor e a crônica esportiva no Brasil, p. 40-41. 
profissionais que recusam as obrigações do discurso canônico jornalístico e que, ao mesmo tempo, recusam as formulações padrão que os "entendidos" do futebol procuram explorar, ao circunscrever suas análises apenas ao âmbito pragmático da disputa. ${ }^{27}$

Pois bem, as crônicas da coluna "Tiro Livre",28 como veremos adiante, inserem-se no campo do jornalismo esportivo concomitantemente como uma escrita de exceção e de negociação de autoridade discursiva sobre os temas que aborda. É uma escrita de exceção, que se configura como crônicas escritas por uma "mulher" e não se limitam a períodos pontuais como a Copa do Mundo. Ao contrário, é uma coluna marcada por ser periódica e longeva: é escrita semanalmente pela autora no jornal Estado de $\operatorname{Minas}^{29}$ e, desde seu início em 2009, além de campeonatos regionais, nacionais e intercontinentais, possui crônicas sobre megaeventos como as Copas do Mundo de 2010 e 2014 e as Olimpíadas de 2012. Para além dessa diferença, em relação às crônicas tradicionais, temos que a "Tiro Livre" é uma negociação de fala sobre o discurso hegemônico relativo ao

\footnotetext{
${ }^{27}$ MARQUES. A função autor e a crônica esportiva no Brasil, p. 49.

${ }^{28}$ Em uma entrevista realizada por Izabela Cardoso para a Associação Mineira de Cronistas Esportivos, Kellen Cristina, a autora da coluna "Tiro Livre" diz que: "A minha vida toda trabalhei dentro do jornal Estado de Minas. Nos Diários Associados, participei de programas da TV Alterosa, do Primeira Página, que era um telejornal pela manhã, parceria entre $\circ E M$ e a Alterosa; além do site Superesportes. Transitei em várias áreas, mas dentro do próprio grupo. Antes de eu me formar, havia um curso dado pela Universidade de Navarra, da Espanha, que durante uma semana havia uma imersão dentro do jornal. Fui uma das selecionadas para fazer parte da segunda turma. Ao terminar o curso, você ia para uma editoria de seu interesse. $O$ meu era só a de Esportes. Fiz jornalismo porque queria trabalhar com esporte desde muito nova [...]. Comecei cobrindo a Copa Centenário de Futebol Amador, com 22, 23 anos. Em 2000 fui estudar inglês fora do país, e, no ano seguinte, abriu uma vaga no Esporte do EM e o Arnaldo Viana, um dos editores, pediu que eu retornasse ao jornal. Apareceu uma carta de denúncias contra a Federação Mineira de Futebol, e eu pedi para fazer a cobertura. [...] Em 2002, me tornei setorista do Atlético, 24 horas cobrindo o clube, até final de 2005. Depois, passei a fazer matérias especiais na redação, cobrindo as férias de algum setorista, até que, em 2008, o diretor de redação Josemar Gimenez me convidou para ser colunista do Esporte com a ida do Eduardo Almeida Reis para a editoria de Gerais. Uma coluna quase que diária, cinco vezes na semana. Menos no domingo e às quartas, que eram o Tostão. Em 2010, virei subeditora de Esportes, e a coluna passou a ser publicada às sextas-feiras".

${ }^{29} \mathrm{O}$ jornal Estado de Minas é o periódico de maior alcance e circulação em Minas Gerais. Possui uma tiragem de aproximadamente 73 mil exemplares nos dias de semana e de 119 mil exemplares nos fins de semana. $\mathrm{Na}$ grande Belo Horizonte atinge 531 mil leitores, dos quais $53 \%$ são homens, $47 \%$ são mulheres, $27 \%$ estão na faixa etária de 20 a 29 anos e $26 \%$ na classe social C. Estes dados estão disponíveis em: https://goo.gl/JDtVv3. A clivagem editorial deste periódico é politicamente ligada a setores conservadores de direita e economicamente ligada a lógica comercial neoliberal. Para uma reflexão sobre como essa, e qualquer outra, clivagem cerceia a autonomia do jornalista e impõe pressões sobre suas pautas, ver: BOURDIEU. Sobre a Televisão, p. 104. NEVEU. Sociologia do jornalismo, p. 84, 124.
} 
futebol, pois, apesar de serem escritos por uma jornalista esportiva, seus temas extrapolam as narrativas ligadas a táticas, ao jogo em si, indo na direção da narrativa que explora o íntimo, o privado e suas curiosidades. Nesse ponto, ficam algumas interrogações: por que negociação? Essas não são justamente algumas das características da crônica como gênero literário ligado ao jornal?

Antônio Cândido define a crônica como um gênero literário que contempla as questões do cotidiano: as dimensões do microssocial são abordadas de maneira íntima. ${ }^{30}$ Um texto divertido de consumo imediato - efêmero, uma narrativa "despretensiosa, insinuante, reveladora", "aparentemente uma conversa fiada" que esconde, na maioria das vezes, uma forte crítica social. Uma narrativa que "busca a oralidade na escrita" e comunica com simplicidade ao leitor questões complexas com maior efetividade. Couto, ao tratar das características que definem as crônicas esportivas, acrescenta que se tratam de narrativas repletas de emotividade e sentimentos em uma profunda inter-relação entre o público e o privado.

Ou seja, se as crônicas, enquanto gênero discursivo, já eram capazes de estabelecer estes parâmetros de exploração dos sentimentos e emoções, os esportes tenderam a ampliar este espectro, devido ao seu impacto no ser humano, nas paixões clubísticas, na rivalidade entre times, nas consequências de determinadas derrotas e vitórias, nas alegrias e tristezas do homem e cidadão comum ao mais rico, etc. ${ }^{31}$

Enfim, como indicam Arrigucci ${ }^{32}$ e Couto, ${ }^{33}$ a crônica é um texto híbrido que joga com fatos e ficções, com literatura e jornalismo, e que tem seu espaço em periódicos. Certamente, há diferenças entre crônicas escritas em diferentes regiões do país. Caprano ${ }^{34}$ aponta para algumas dessas diferenças ao desconstruir e dissociar a imagem de Mário Filho como o "inventor do jornalismo esportivo". No entanto, extrapola o escopo desse artigo a discussão das semelhanças e diferenças entre as crônicas escritas em Minas Gerais em contraposição a outros estados brasileiros.

\footnotetext{
${ }^{30}$ CANDIDO. A vida ao rés do chão, p. 89-99.

${ }^{31}$ COUTO. Cronistas esportivos em campo, p. 64.

${ }^{32}$ ARRIGUCCI JR. Fragmentos sobre a crônica.

${ }^{33}$ COUTO. Cronistas esportivos em campo.

${ }^{34}$ CAPRANO. Mário Filho e a "invenção" do jornalismo esportivo profissional.
} 
Dessa forma, nesse artigo, escolhemos abordar as cinco crônicas escritas pela jornalista em virtude da Copa de 2010 na África do Sul. As suas crônicas possuem, em maior ou menor medida, as características relacionadas acima. Não obstante, gostaríamos de refletir, a partir de suas crônicas, sobre a possibilidade de uma escrita que fuja da lógica masculina hegemônica - socialmente desejável - de olhar para o futebol. Assim, tomaremos como possibilidade uma "escrita feminina", não tratando "mulher" como uma entidade, mas pensando nas diferenças e considerando, também, que para as pessoas às quais esse gênero fora atribuído, a norma construída sobre essa suposta identidade implica em "submissão, falta de autonomia, dependência e incapacidade de se colocar como sujeito". 35 Para tal, seguiremos o percurso por dois caminhos: iniciaremos com a discussão sobre a escrita feminina e, em seguida, analisaremos as narrativas entremeadas nas crônicas da coluna "Tiro Livre".

\section{A ESCRITA É UMA EXPERIÊNCIA GENERIFICADA?}

Algumas escritoras vão levantar a importância de falar de uma escrita feminina quase como uma forma de dar valor àquilo que fora retirado das "mulheres" ao longo do tempo: a possibilidade de fazer sua voz ser ouvida por meio da escrita.

Colasanti afirma ser uma "mulher" escritora e questiona a frequência da pergunta que associa "mulher" e escrita, a saber, "existe uma escrita feminina?". Ela se propõe a não aceitar essa pergunta passivamente, pois a própria pergunta seria uma afronta à medida que revela a dúvida sobre a existência de uma literatura feminina: "Eu, que a partir da escrita estou há anos empenhada em construir a arquitetura de uma voz que sendo minha é feminina, declaro-me ofendida com a pergunta". ${ }^{36}$

Segundo essa autora, a dúvida indicaria que a coisa perguntada é imperceptível, inconstante e fraca ao ponto de não existir. Portanto, esse questionamento não é inocente, mas, ao contrário, está circunscrito por uma

\footnotetext{
${ }^{35}$ AZEREDO. Preconceito contra a "mulher", p. 53.

${ }^{36}$ COLANSANTI. Por que nos perguntam se existimos, p. 324.
} 
dinâmica de poder que nega o uso das palavras pelas "mulheres" ao conferir uma subqualificação à literatura feminina. Há uma compreensão de que o pequeno e restrito acesso à fala das "mulheres" já é excessivo e, por isso, necessita ser encoberto e interrompido. A autora compreende que essa dinâmica autoriza as "mulheres" a narrar os textos dos outros, já que a elas é permitido, por meio da oralidade, transmitir "os elementos culturais da sociedade patriarcal". Entretanto, a elas permanece vetada a possibilidade de escrever e narrar seus próprios textos (suas próprias experiências), já que representaria uma ameaça, uma transgressão ao controle masculino sobre a fala, a escrita e a experiência feminina.

Joan Scott ${ }^{37}$ entende que a experiência e a linguagem são, além de generificadas (apesar de não utilizar desse termo em seu texto), relacionais, no sentido de que "precisamos dar conta dos processos históricos que, através dos discursos, posicionam sujeitos e produzem suas experiências". ${ }^{38}$ No argumento dessa essa autora, não faz sentido separar a linguagem da experiência, pois é no amálgama desses dois fenômenos que se constroem sujeitos numa multiplicidade discursiva afeita a contextos sócio-históricos específicos. No mais, as experiências, apesar de plurais, materializam-se nos discursos de sujeitos historicamente situados. Elas, as experiências, até podem narrar eventos individuais que só são possíveis dentro de contextos de fala e ação coletiva. São, nesse sentido, plurais e situadas, o que faz crer que as escritas também o seriam. É isso que Haraway 39 argumenta quando propõe pensar em escritas de "mulheres", no plural. A partir de uma perspectiva feminista sobre a ciência, essa autora defende uma "política de posicionamento". Ou seja, as maneiras de olhar, escutar e escrever sobre a realidade são matizadas por saberes localizados, corporificados, mediados por experiências e conexões entre as subjetividades envolvidas na pesquisa.

Outras autoras procuram repensar a escrita por meio do gênero, apontando para a necessidade de romper com essas restrições de um binarismo predeterminado e extrapolar uma experiência essencial masculina ou feminina na escrita.

\footnotetext{
${ }^{37}$ SCOTT. Experiências.

${ }^{38}$ SCOTT. Experiências, p. 27.

${ }^{39}$ HARAWAY. Saberes localizados.
} 
Leal, ${ }^{40}$ ao problematizar o artigo de Richard, ${ }^{41}$ propõe que as identidades não são fixas e, assim como as escritas, estão em constante negociação. Portanto, não haveria nem uma identidade feminina e muito menos uma escrita feminina per se. Segundo compreende Leal,

esse princípio nos conduziria a admitir o raciocínio de que a palavra escrita pode ou não, se assim o pretender o sujeito escritural, se desterritorializar do lugar de enunciação sexual do eu biográfico ou, ainda, da identidade sexual desse eu. Pensado nesses termos, compreenderíamos as relações entre escrita e gênero através de uma perspectiva performático simbólica das identidades sexuais, na qual estivesse subjacente um jogo ininterrupto, dialético e ambíguo de vozes e de eus amparado não só pela fluidez, movimentação e continuum de estratégias e táticas escriturais postas em ação, intencionalmente ou não, na materialidade literária, mas por esse caráter poroso, maleável e volátil da constituição do gênero (grifos da autora). ${ }^{42}$

Na mesma direção, Wittig43 afirma que não há uma escrita feminina porque a categoria feminina é uma abstração que serve, na sua naturalização, a matriz heterossexual compulsória. Essa matriz constrói as categorias masculinas e femininas e associa a cada termo outras características binárias, contendo valores assimétricos e tornando o sexo e o gênero em uma substância a-histórica - o que a autora chama de "mentalidade hétero". Nesse sentido, a expressão "escrita feminina" designaria um tipo de produção peculiar ligada à biologia, ou a uma pretensa natureza da "mulher". Uma produção que negaria a dedicação, o esforço, o trabalho e a historicidade do processo de construção do texto.

Em outras palavras, segundo as normas sociais, o texto sairia das tintas das canetas, ou das teclas do computador manuseadas pelas mãos femininas naturalmente, tal qual os afazeres domésticos, a predisposição para o cuidado e um certo tipo de sensibilidade e comportamento. A autora indica, ainda, que a escrita considerada por essa perspectiva é uma escrita somente possível em termos de normas vinculadas à heterossexualidade universal e compulsória. Consequentemente, o que é estabelecido tanto pela matriz heterossexual quanto

\footnotetext{
${ }^{40}$ LEAL. Gênero e escrita.

${ }^{41} \mathrm{RICHARD}$. Intervenções crítica.

${ }^{42}$ LEAL. Gênero e escrita, p. 2.

${ }^{43}$ WITTIG. The point of view: universal or particular?
} 
pela mentalidade heterossexual, seriam formas de dominação política que inviabilizam a possibilidade de fala e também a escrita das minorias que não estão incluídas em nenhuma dessas formas.

O que gostaríamos de reter desse debate sobre as divergências da possibilidade de uma escrita feminina é a evidência, compartilhada pelas autoras supracitadas, de que as "mulheres", na lógica da escrita formal, até podem falar com suas próprias vozes, desde que mediadas pelas normas masculinas "normásculas", neologismo criado por Chabaud-Rychter et al.,44 para, em outro contexto, denunciar e discutir os modelos canônicos masculinos de se fazer e escrever ciência. Esse mesmo processo pode ser percebido no campo da crônica esportiva, no sentido de que os temas e as formas de pensá-los parece ser controlado pelos "homens". E, nesse caso, as "mulheres" ficam expostas a uma dupla concessão (da escrita e do futebol).

\section{NARRANDO A COPA DA ÁFRICA}

A Copa do Mundo de 2010, além de ter sido a primeira no continente africano, foi marcada por fatos pitorescos. A bola, chamada Jabulani, deu trabalho para os jogadores por ser considerada incontrolável: difícil de dominar, difícil de ter precisão nos passes e chutes e ainda tomava efeitos que complicava a vida dos goleiros. Essa foi a Copa em que a anfitriã foi eliminada na primeira etapa. A Copa em que Diego Maradona comandou a Seleção Argentina como técnico. A Copa em que o Brasil perdeu para a Holanda, depois de um descontrole emocional que resultou em agressão e na expulsão de Felipe Melo. A Copa em que a seleção uruguaia reencontrou seu futebol centenário e ficou entre as quatro melhores seleções do mundo. E, por fim, foi a Copa vencida pela Espanha, por meio de um estilo de jogo que valorizava as trocas de passes entre os jogadores de forma cadenciada e constante, estilo que foi denominado "tic-taca", em cima da Holanda.

\footnotetext{
${ }^{44}$ CHABAUD-RYCHTER; DESCOUTURES; DEVEREUX; VARIKAS. Introdução: questões de gênero nas Ciências Sociais "normásculas".
} 
As crônicas de "Tiro Livre" exploraram esses fatos que compuseram a Copa da África do Sul. As narrativas se iniciaram em 11 de junho de 2010 com o título de “A Copa para os íntimos" e se encerraram em 09 de julho de 2010 com a coluna intitulada "Pela lógica, dá Espanha".

Nessas cinco semanas de evento, foram escritas cinco crônicas que passearam pelos seguintes temas: os apelidos dos times; a vida dos árbitros para além das quatro linhas; a associação da bola com o comportamento feminino e as relações familiares - irmãos jogando no mesmo time e em times separados.

No que concerne aos apelidos evocados das seleções são: "Bafana Bafana", com referência à África do Sul; "Soccerros", referente à Austrália; "All Whites", o apelido da Nova Zelândia; "Mannschaft" da Alemanha; "Le blues" da França; "La Bicolor", que é uma referência a Honduras; "El Tri”, apelido dado ao México; "Raposas do deserto" referenciando a Argélia e "Leões Indomáveis", como é conhecida a Seleção de Camarões. Para além dos apelidos, a autora aproxima as seleções mencionadas do cotidiano dos leitores, como podemos observar no trecho:

Os jogos estarão no seu café da manhã, almoço e jantar. [...] Jogadores e técnicos vão virar seus chegados. Em toda relação próxima que se preze você vai saber os mínimos detalhes da turma. E para ajudar a estreitar mais rapidamente esses laços, "Tiro Livre" apresenta alguns dos apelidos das seleções que começam, hoje, a luta pela taça. ${ }^{45}$

Os árbitros também são lembrados com uma lógica mais intimista. Eles são designados em sua vida privada na crônica "De japonês a uzbeque". Aqui, é relevante observar a forma como ela constrói os personagens, mantendo uma humanidade que muitas vezes acaba ignorada no contexto do futebol, principalmente para o árbitro, tido como um inimigo em potencial.

Os casos mais, digamos assim, pitorescos são os do uzbeque Ravshan Irmato, destacado para Argentina x Alemanha, e do guatemalteco Carlos Batres, que apitará Paraguai x Espanha. Ravshan caiu mesmo no gosto da Fifa, afinal esteve também na abertura da Copa entre África do Sul e México. Agora trabalhará em um dos confrontos mais aguardados da

\footnotetext{
${ }^{45}$ CRISTINA. A Copa para os íntimos, p. 15.
} 
rodada. Aos 32 anos, ele é o mais jovem entre os 30 árbitros que foram para a Copa, dá aula de futebol em escolas da capital de seu país, Tashkent, e tomou gosto pelo apito com o pai, também árbitro. Zagueiro de carreira frustrada e cientista fora das quatro linhas, Batres, de 42 anos, vai ter que enfrentar o orgulho ferido paraguaio. ${ }^{46}$

É importante destacar uma forma particular de se escrever sobre os meandros do futebol. Ela se utiliza de elementos do cotidiano a fim de trazer uma experiência palpável para o leitor, como é esperado do estilo de escrita. Isto é feito, todavia, lançando mão de elementos que regularmente deslocam o futebol do mundo público, ao qual ele é designado, para o privado, se é que podemos delimitar uma separação tão clara entre esses dois âmbitos da vida. Fato é que os aspectos tratados por ela, que trazem um tom intimista para seu texto, não têm espaço nas "crônicas masculinas", sempre preocupadas com elementos que mostrem todo um conhecimento formal, ainda que não se apresente deste modo, do esporte a ser tratado.

Dentre os temas evocados, há, também, a generificação da bola, feita pela autora:

Entre algumas teorias a respeito da primeira rodada meio fraquinha da Copa, fico com a mais exótica, para combinar com a excentricidade do país-sede. É a vingança da Jabulani. A bola foi tão difamada antes de rolar que resolveu dar o troco. [...] todo mundo pegou no pé da Jabulani e, com isso, acabou ferindo o orgulho da moça. Nada pior do que uma mulher magoada, acreditem. Ela vinga mesmo. É o que está fazendo a Jabulani. Mas, como toda moçoila que se preze, tem coração mole. Pode ser, então que ela já tenha perdoado os mortais do esporte bretão e, a partir de agora, role mais faceira, pelos gramados africanos, deixando brilhar os craques que tanto esperamos assistir! ${ }^{47}$

Essa crônica gerou certo incômodo no momento em que foi analisada. Isso se deu pelo fato de a autora comparar a "Jabulani" a uma "mulher". Aparentemente, não seria um problema tão grave, até nos atentarmos para o fato de que, numa coletiva de imprensa no dia 31 de maio de 2010, Felipe Melo faz uma declaração misógina, racista e permeada por preconceitos de classe com essa mesma

\footnotetext{
${ }^{46}$ CRISTINA. De japonês a uzbeque, p. 8.

${ }^{47}$ CRISTINA. A vingança da Jabulani, p. 15.
} 
"metáfora" - a bola comparada a uma "mulher": "A outra bola é igual à mulher de malandro: você chuta e ela continua ali. Essa de agora é igual patricinha, que não quer ser chutada de jeito nenhum". 48 Não sabemos até que ponto a autora fez referência a essa fala, porém pudemos apreender um elemento novo em sua crônica. Apesar da comparação infeliz, ela se distancia das declarações dadas pelo jogador ao trazer a bola se vingando das declarações que a difamaram.

A despeito dessa polêmica apresentada anteriormente, é importante ressaltar que a autora, novamente, por meio da personificação de um objeto, aproxima o futebol do âmbito privado. Ela se utiliza da dificuldade de jogar - um elemento da partida -, que até então poderia ser encontrado em outras crônicas e textos sobre o espetáculo futebolístico, e faz um deslocamento que torna a dinâmica do texto inovadora, ainda que toda construção do texto remeta a uma negociação com a norma vigente no contexto - não fugir tanto do que é estabelecido.

Por fim, no que tange às relações familiares, ela fala de irmãos que jogam na mesma seleção e em seleções diferentes, que era algo inédito até o momento. Todavia, traz esse elemento como forma de "chutar" que a Copa seria vencida pela Espanha para completar os fatos inusitados do evento ocorrido na África do Sul:

[...] um campeão inédito na decisão entre Holanda e Espanha, Desfecho bem emblemático para uma competição marcada pelo sabor da primeira vez. Calhou que em gramados africanos, ocorreu muita coisa nova, algumas até surpreendentes. Duelo entre irmãos, parcerias inusitadas, eliminações precoces... a lista é grande, então, vamos a ela. [...] 0 torneio na África teve um inédito duelo entre irmãos - do ganês Kevin-Price Boateng contra o alemão Jerome Boateng -, além de outro marco familiar: Honduras contou com três irmãos em seu grupo, outro fato inédito em Copas. A mamãe Palácios deve ter ficado orgulhosa ao ver Jerry, Wilson e Jhonny juntos. Poderia até ser um quarteto, já que Milton chegou a disputar 14 jogos pela seleção de seu país, mas acabou não sendo convocado. [...] E, se houver alguma lógica nesta crônica, a taça vai acabar com a Espanha que, pela primeira vez, chega a uma final. ${ }^{49}$

Acrescentamos que é importante mencionar que não necessariamente o conteúdo se torna um tema novo no que diz respeito às crônicas esportivas - nem

\footnotetext{
${ }^{48}$ Fala retirada do site Globo Esporte: https://goo.gl/6oDTBo.

${ }^{49}$ CRISTINA. Pela lógica, dá Espanha, p. 8.
} 
as relações consanguíneas, nem os palpites sobre uma partida, nem personagens focalizados na vida cotidiana. Como nos faz crer Hollanda ${ }^{50}$ quando põe em destaque, na década de 1930, as mudanças propostas por Mário Filho para o jornalismo esportivo em $O$ Globo e mais tarde no Jornal dos Sports:

Os novos procedimentos de reportagem incluíam entrevistas e depoimentos dos jogadores de futebol, transformados em ídolos da cultura de massa emergente, e passíveis, portanto, de compor relatos nos moldes de "história da vida privada". O cotidiano e o íntimo dos atletas passavam a interessar a pauta do jornalismo, que vivia à cata de curiosidades e procurava devassar, como dizia a chamada da revista da época, a "vida do crack". 51

Porém, o fato de evocar tais temas como forma de tornar o evento mais próximo dos leitores e relacioná-los, torna-se um ponto inovador na escrita da autora em "Tiro Livre". Entretanto, isso não necessariamente indica que essa forma de evocar os fatos têm alguma relação com o gênero da autora.

\section{CONSIDERAÇõES FINAIS}

Encaminhando para a finalização desse texto, é importante expressarmos o que foi pensado acerca da coluna tratada, "Tiro Livre", sobretudo tendo em vista o que fora mencionado sobre o deslocamento da escrita tradicional, protagonizada por uma "mulher", diferente do que é tido como desejável dentro da tradição do meio futebolístico. Antes que isso seja feito, é fundamental retomar o que entendemos como normas de gênero e as dinâmicas de poder que as permeiam.

Gênero, nesse trabalho, é entendido como o processo que significa os corpos inseridos em um contexto cultural. Ele acaba sendo o elemento exterior que convoca os sujeitos aos quais ele atribui, ou não, certa inteligibilidade. Assim, somente a partir desse processo de subjetivação, temos um sujeito, inscrito nas hierarquias sociais. Entretanto, não se dá de forma tão simples, tendo em vista que, como dito anteriormente, há, nessas normas vigentes, certas naturalizações do que

\footnotetext{
${ }^{50}$ HOLLANDA. O cor-de-rosa.

${ }^{51}$ HOLLANDA. O cor-de-rosa, p. 87-88.
} 
é considerado feminino e masculino, que tomam como base elementos corporais redutores, até mesmo o que é considerado corpo, na dinâmica de uma "metafísica da substância", como diria Butler. ${ }^{52}$

Tendo isso claro, é importante distinguir as experiências normativas históricas para "mulheres" e "homens". Ao delegar as "mulheres" ao âmbito privado, usando, para tanto, características tidas como biológicas, inatas e imutáveis, estabeleceram-se ao longo do tempo assimetrias sociais: o poder sempre estivera vinculado ao âmbito público, território designado às masculinidades. Tais construções, provavelmente, foram facilitadas por esse processo. Afinal, quem dominava a escrita, a política e, consequentemente, o que seria relatado na história oficial? Deste modo, as "mulheres" foram alijadas da escrita e, assim, não podemos diminuir ou ignorar a marginalização da escrita feminina na nossa sociedade. ${ }^{53}$ No caso dos textos tratados nessa análise, devemos acrescentar, lembrando do não-lugar feminino na escrita, o fato de que essas crônicas são escritas por uma "mulher" que se atreve a falar sobre o futebol: outro espaço vetado às feminilidades.

Levando em conta toda essas exclusões das "mulheres" na escrita, no futebol e, portanto, na escrita futebolística, bem como a forma de retratar esse contexto, que produz alguns deslocamentos, não estamos entendendo, pois, que esse olhar ou essa forma de tratar do campo esportivo se dê por um elemento biológico que distinguiria os sujeitos na sua forma de compreender, apreender e significar as experiências. ${ }^{54}$ Tampouco estamos entendendo que apenas pela marcação do gênero, pensando este como uma norma que enquadra sujeitos e corpos, a autora tem seu olhar necessariamente modificado, destoando completamente dos discursos hegemônicos vigentes no jornalismo esportivo e nas formas de fazer crônica esportiva. Estamos chamando a atenção para os diversos sujeitos e os diversos modos de encarar os eventos do mundo do futebol, que, muitas vezes, passam despercebidos por uma série de consensos construídos socialmente como normas, que, ao fornecer reconhecimento a alguns sujeitos

\footnotetext{
${ }^{52}$ BUTLER. Problemas de gênero.

${ }^{53}$ PERROT. As mulheres ou o silêncio da história.

${ }^{54}$ PERROT. Práticas da memória feminina.
} 
sobre suas vivências, naturalizando-as ("futebol é coisa pra macho"), invisibiliza outras possibilidades. Por fim, a participação de uma autora, atípica no contexto tratado, ainda que marcada, constantemente, por concessões, corrobora com a ideia de que as normas são, a todo o tempo, negociadas e renegociadas, sendo, portanto passíveis de ruptura.

\section{REFERÊNCIAS}

ARRIGUCCI JR, Davi. Fragmentos sobre a crônica. In: comentário: ensaios sobre literatura e experiência. São Paulo: Companhia das Letras, 1987, p. 51-66.

AZEREDO, Sandra. Preconceito contra a "mulher": diferença, poemas e corpos. São Paulo: Cortez, 2011.

BOURDIEU, Pierre. Sobre a Televisão. Rio de Janeiro: Jorge Zahar Ed., 1997. BOURDIEU, Pierre. A economia das trocas linguísticas. São Paulo: Editora da Universidade de São Paulo, 2008.

BUTLER, Judith. Corpos que pesam: sobre os limites discursivos do sexo. In: LOURO, Guacira Lopes (org.). O corpo educado: pedagogias da sexualidade. Belo Horizonte: Autêntica, 2000.

BUTLER, Judith. Problemas de gênero: feminismo e subversão da identidade. Rio de Janeiro: Civilização Brasileira, 2003.

BUTLER, Judith. Deshacer el género. Barcelona: Paidos, 2006.

CÂNDIDO, Antônio. A vida ao rés do chão. In: ANDRADE, Carlos Drummond de et al. Para gostar de ler. São Paulo: Ática, 2003, p. 89-99. Disponível em: https://goo.gl/yAx52J. Acesso em: 21 fev. 2018.

CAPRARO, André Mendes. Mário Filho e a "invenção" do jornalismo esportivo profissional. Movimento. Porto Alegre, v.17, n.02, p. 213-224, abr.-jun. 2011.

CARDOSO, Izabela. Personagem de uma história: Kellen Cristina - Estado de Minas. Associação Mineira de Cronistas Esportivos. Disponível em: https://goo.gl/iKXZZz. Acesso em: 26 fev. 2018.

CHABAUD-RYCHTER, Danielle; DESCOUTURES, Virginie; DEVEREUX, Anne-Marie; VARIKAS, Eleni. Introdução: questões de gênero nas Ciências Sociais "normásculas". In:___ (org.). O gênero nas Ciências Sociais: releituras críticas de Max Weber a Bruno Latour. São Paulo: Editora Unesp; Brasília: Editora Universidade de Brasília, 2014. p. 3-24.

CLASTRES, Pierre. Da tortura nas sociedades primitivas. In: A sociedade contra o Estado: pesquisa de antropologia política. São Paulo: Cosac \& Naify, 2003, p. 193-204. 
COLANSANTI, Marina. Por que nos perguntam se existimos. In: RODRIGUES, Carla; BORGES, Laura; RAMOS Tânia Regina de Oliveira (org.). Problemas de gênero. Rio de Janeiro: Funarte, 2016, p. 323-331.

COSTA, Felipe Rodrigues da; NETO, Amarílio Ferreira; SOARES, Antônio Jorge Gonçalves. Crônica esportiva brasileira: histórico, construção e cronista. Pensar a Prática. 10/1, p. 15-31, jan.-jun. 2007.

COUTO, André Alexandre Guimarães. Cronistas esportivos em campo: letras, imprensa e cultura no Jornal dos Sports (1950-1958). Tese (Doutorado em História). Setor de Ciências Humanas, Letras e Artes da Universidade Federal do Paraná, Curitiba, 2016.

CRISTINA, Kellen. A Copa para os íntimos. Estado de Minas. Belo Horizonte 11 jun. 2010. Superesportes: Tiro Livre, p. 15.

CRISTINA, Kellen. A vingança da Jabulani. Estado de Minas. Belo Horizonte 18 jun. 2010. Superesportes: Tiro Livre, p. 15.

CRISTINA, Kellen. Os gringos dos gringos. Estado de Minas. Belo Horizonte 25 jun.2010. Superesportes: Tiro Livre, p. 11.

CRISTINA, Kellen. De japonês a uzbeque. Estado de Minas. Belo Horizonte 02 jul. 2010. Superesportes: Tiro Livre, p. 8.

CRISTINA, Kellen. Pela lógica, dá Espanha. Estado de Minas. Belo Horizonte 09 jul. 2010. Superesportes: Tiro Livre, p. 8.

DUNNING, Eric. O esporte como um domínio masculino: observações sobre fontes sociais da identidade masculina e suas transformações. In:

Sociologia do esporte e os processos civilizatórios. São Paulo: Annablume, 2014, p. 233-254.

FOUCAULT, Michel. Verdade e poder. In: Microfísica do poder. Rio de Janeiro: Graal, 2001, p. 1-14.

FOUCAULT, Michel. A ordem do discurso. São Paulo: Ed. Loyola, 2008.

HARAWAY, Donna. Saberes localizados: a questão da ciência para o feminismo e o privilégio da perspectiva parcial. Cadernos Pagu. Campinas, SP. n. 5, p. 7-41, 1995.

HARGREAVES, Jennifer. Sporting females: critical issues in the history and sociology of women's sports. London: Routledge, 1994.

HOLLANDA, Bernardo Buarque. O cor-de-rosa: ascensão, hegemonia e queda do Jornal dos Sports entre 1930 e 1980. In: HOLLANDA, Bernardo Buarque; MELO, Victor Andrade de. (Org.). O esporte na imprensa e a imprensa esportiva no Brasil. Rio de Janeiro: 7Letras, 2012, p. 80-106.

LEAL, Juliana. Gênero e escrita. Revista Ártemis. João Pessoa, PB, v. 5, dez., 2006.

LEVI-STRAUSS, Claude. Lições de escrita. In:

Paulo: Companhia das Letras, 1996, p. 278-287. Tristes Trópicos. São 
MARQUES, José Carlos. A função autor e a crônica esportiva no Brasil: representações da Copa do Mundo em alguns jornais paulistas e cariocas. LOGOS 33. Comunicação e Esporte, Rio de Janeiro, v. 12, n. 2, p. 39-50, 2010.

NEVEU, Érik. Sociologia do jornalismo. São Paulo: Ed. Loyola, 2006.

PERROT, Michelle. Práticas da memória feminina. Revista Brasileira de História. São Paulo, v. 9, n. 18, p. 9-18, ago.-set., 1989.

PERROT, Michelle. As mulheres ou o silêncio da história. Bauru, SP: Edusc, 2005.

RIBEIRO, André. Os donos do espetáculo: histórias da imprensa esportiva do Brasil. São Paulo: Terceiro Nome, 2007.

RICHARD, Nelly. Intervenções críticas: arte, cultura, gênero e política. Belo Horizonte: Editora UFMG, 2002.

RUBIN, Gayle. O tráfico de mulheres: notas sobre a "economia política" do sexo. In: Políticas do sexo. São Paulo: Editora UBU, 2017, p. 9-61.

SCOTT, Joan. Experiências. In: DA SILVA, Alcione; LAGOS, Mara Coelho de Souza; RAMOS, Tânia Regina de Oliveira. (Org.). Falas de gênero: teorias, análises, leituras. Florianópolis: Editora Mulheres, 1999, p. 21-56.

THERBERGE, Nancy. Gender and sport. In: COAKLEY, Jay; DUNNING, Eric. (Ed.). Handbook of sports studies. London: Sage, 2000, p. 322-334.

WHANNEL, Garry. Sport and the media. In: COAKLEY, Jay; DUNNING, Eric. (Ed.). Handbook of sports studies. London: Sage, 2000, p. 291-308.

WITTIG, Monique. The point of view: universal or particular? In:

straight mind and other essays. Boston: Beacon Press, 1992, p. 60-67. . The 